\title{
Remote sensing of near-infrared chlorophyll fluorescence from space in scattering atmospheres: implications for its retrieval and interferences with atmospheric $\mathrm{CO}_{2}$ retrievals
}

\author{
C. Frankenberg ${ }^{1}$, C. O'Dell ${ }^{2}$, L. Guanter ${ }^{3}$, and J. McDuffie ${ }^{1}$ \\ ${ }^{1}$ Jet Propulsion Laboratory, California Institute of Technology, Pasadena, USA \\ ${ }^{2}$ Colorado State University, Fort Collins, CO, USA \\ ${ }^{3}$ Atmospheric, Oceanic and Planetary Physics, University of Oxford, UK \\ Correspondence to: C. Frankenberg (christian.frankenberg@jpl.nasa.gov) \\ Received: 24 February 2012 - Published in Atmos. Meas. Tech. Discuss.: 29 March 2012 \\ Revised: 12 June 2012 - Accepted: 20 July 2012 - Published: 28 August 2012
}

\begin{abstract}
With the advent of dedicated greenhouse gas space-borne spectrometers sporting high resolution spectra in the $\mathrm{O}_{2}$ A-band spectral region $(755-774 \mathrm{~nm})$, the retrieval of chlorophyll fluorescence has become feasible on a global scale. If unaccounted for, however, fluorescence can indirectly perturb the greenhouse gas retrievals as it perturbs the oxygen absorption features. As atmospheric $\mathrm{CO}_{2}$ measurements are used to invert net fluxes at the land-atmosphere interface, a bias caused by fluorescence can be crucial as it will spatially correlate with the fluxes to be inverted. Avoiding a bias and retrieving fluorescence accurately will provide additional constraints on both the net and gross fluxes in the global carbon cycle. We show that chlorophyll fluorescence, if neglected, systematically interferes with full-physics multiband $X_{\mathrm{CO}_{2}}$ retrievals using the $\mathrm{O}_{2} \mathrm{~A}$-band. Systematic biases in $X_{\mathrm{CO}_{2}}$ can amount to $+1 \mathrm{ppm}$ if fluorescence constitutes $1 \%$ to the continuum level radiance. We show that this bias can be largely eliminated by simultaneously fitting fluorescence in a full-physics based retrieval.

If fluorescence is the primary target, a dedicated but very simple retrieval based purely on Fraunhofer lines is shown to be more accurate and very robust even in the presence of large scattering optical depths. We find that about $80 \%$ of the surface fluorescence is retained at the top-of-atmosphere, even for cloud optical thicknesses around 2-5. We further show that small instrument modifications to future $\mathrm{O}_{2}$ Aband spectrometer spectral ranges can result in largely reduced random errors in chlorophyll fluorescence, paving the way towards a more dedicated instrument exploiting solar absorption features only.
\end{abstract}

\section{Introduction}

Both the Greenhouse Gases Observing Satellite (GOSAT) (Hamazaki et al., 2005; Kuze et al., 2009) and the Orbiting Carbon Observatory (OCO) (Crisp et al., 2004) aim at retrieving atmospheric greenhouse gas column averaged mixing ratios (denoted $X_{\mathrm{CO}_{2}}$ or $X_{\mathrm{CH}_{4}}$ ) with high enough accuracy and precision to improve our current understanding of land-atmosphere fluxes on regional scales. OCO, targeting $\mathrm{CO}_{2}$ exclusively, suffered a launch failure in early 2009 , but an instrument copy is being built and the launch of OCO- 2 is planned for 2014.

The term full-physics algorithm is commonly used in the atmospheric remote sensing community for retrievals based on the full modeling of the radiative transfer instead of parameterizations or a decoupling of the retrieval of trace gas slant column densities and radiative transfer modeling. A typical full-physics algorithm for the retrieval of $X_{\mathrm{CO}_{2}}$ (Bösch et al., 2006; Butz et al., 2009; O’Dell et al., 2011) concurrently employs three spectral bands, centered around $0.76 \mu \mathrm{m}\left(\mathrm{O}_{2}\right.$ A-band), $1.61 \mu \mathrm{m}$ (weak $\mathrm{CO}_{2}$ band) and $2.06 \mu \mathrm{m}$ (strong $\mathrm{CO}_{2}$ band). By using this multi-channel approach, $X_{\mathrm{CO}_{2}}$, surface albedos as well as aerosol properties can be retrieved concurrently. The aerosol properties deserve special interest in this study as they are mostly constrained by the strong absorption features of atmospheric $\mathrm{O}_{2}$ at $0.76 \mu \mathrm{m}$ as well as strong $\mathrm{CO}_{2}$ features at $2.06 \mu \mathrm{m}$. Since atmospheric scattering can enhance or shorten the light-path of recorded photons, it will affect the $X_{\mathrm{CO}_{2}}$ retrievals if retrieved scattering properties are biased. Frankenberg et al. (2011a) found that near-infrared (NIR) chlorophyll fluorescence $\left(F_{\mathrm{s}}\right)$ cannot 
be unambiguously distinguished from the effect of scattering on the depth and shape of atmospheric $\mathrm{O}_{2}$ absorption features in the $0.76 \mu \mathrm{m}$ range. However, the potential propagated impact on $X_{\mathrm{CO}_{2}}$ retrievals was not explicitly quantified.

The goals of this paper are twofold: first, to quantify and mitigate the potential impact of chlorophyll fluorescence on $X_{\mathrm{CO}_{2}}$ retrievals, and second, to quantify how accurately TOA (top-of-atmosphere) fluorescence can be retrieved and how it relates to fluorescence at the surface level. While the first goal is of a technical nature and relates to the $\mathrm{CO}_{2}$ remote sensing community, the second one has implications regarding the applicability of remotely sensed chlorophyll fluorescence, especially given that real retrievals are now being successfully performed using GOSAT data (Joiner et al., 2011; Frankenberg et al., 2011b; Guanter et al., 2012; Joiner et al., 2012).

The paper is structured as follows: Sect. 2 gives an overview of the chlorophyll fluorescence signal and its application in plant physiology and vegetation remote sensing. Section 3 describes the implementation of the fluorescence emission in a radiative transfer model for simulations as well as in a full-physics retrieval algorithm. Section 4 shows simulation results as to how fluorescence impacts scattering and $X_{\mathrm{CO}_{2}}$ retrievals. Section 5 focuses on the retrieval of the chlorophyll fluorescence signal itself and discusses how $F_{\mathrm{s}}$ retrieved at TOA relates to the emission from the plant at surface level in the presence of scattering. It also provides an overview on how future satellites with similar measurement principles can improve upon current and planned ones. The audience for this manuscript may be rather diverse, with interest either in $X_{\mathrm{CO}_{2}}$ or fluorescence retrievals. Thus, we tried to keep Sect. 4 (focused on $X_{\mathrm{CO}_{2}}$ biases) and Sect. 5 (focused on chlorophyll fluorescence itself) as self-contained as possible in case the general reader wants to skip sections.

\section{Chlorophyll fluorescence}

Shortwave energy obtained from a laser or a visible light pulse with laboratory or field instruments, or by the sun, is collected within vegetation by chlorophyll. Under optimal conditions, most of this energy is routed through photosynthesis, but typically some energy is dissipated as heat or reemitted via fluorescence at longer wavelengths in the 660$800 \mathrm{~nm}$ window. When determined under natural conditions outdoors, the fluorescence obtained is referred to as solarinduced chlorophyll fluorescence (Krause and Weis, 1991; Baker, 2008, and references therein). Fluorescence intensity is thus an indicator of photosynthetic activity. At the surface level, the fluorescence emission $\left(F_{\mathrm{s}}\right)$ adds a small offset of up to about $10 \mathrm{~W} \mathrm{~m}^{-2} \mathrm{sr}^{-1} \mu \mathrm{m}^{-1}$ (Entcheva Campbell et al., 2008) in the two emission peaks around 690 and $740 \mathrm{~nm}$, the latter of which encompasses the strong $\mathrm{O}_{2}$ A-band around $765 \mathrm{~nm}$. The broad-band emission leads to a filling-in of solar and telluric absorption features (Plascyk and Gabriel, 1975), and current retrieval techniques at the ground and airborne scales mostly focus on using the $\mathrm{O}_{2}$ absorption features for its retrieval. See Meroni et al. (2009) for a literature overview of common retrieval techniques for fluorescence signals used to study the photosynthetic apparatus (e.g., Krause and Weis, 1984, 1991; Flexas et al., 2002; Moya et al., 2004; Rascher et al., 2009) and stress related changes in gross primary production (GPP) (Damm et al., 2010; Daumard et al., 2010). However, there are still uncertainties regarding the contribution of Photosystem I (PSI, Pfuendel, 1998) to the chlorophyll fluorescence signal in the 755-770 nm window under natural and stressed conditions. The primary driver of fluorescence is certainly absorbed photosynthetically active radiation, but the inter-play between photosynthesis and fluorescence yield in steady-state conditions may require further research before fluorescence modeling (Van der Tol et al., 2009) offers a consolidated physiology-based link between NIR fluorescence and photosynthetic efficiency. A good correlation of space-based fluorescence retrievals with gross primary production on the coarser regional scale, however, was demonstrated in Frankenberg et al. (2011b) and Guanter et al. (2012).

In Frankenberg et al. (2011a), we have shown that the use of $\mathrm{O}_{2}$ lines in fluorescence retrievals cannot be readily applied if only the $\mathrm{O}_{2}$ A-band is measured and a ground reference value is unavailable. However, Fraunhofer lines (absorption features in the solar atmosphere) can be used to disentangle the fluorescence emission from scattering effects, a technique used in the quantification of chlorophyll emission from GOSAT data (Joiner et al., 2011, 2012; Frankenberg et al., 2011b).

To put the analysis in the following sections into perspective, Fig. 1 shows a 2-yr average of chlorophyll fluorescence in terms of percent of continuum level radiance. Regional averages can reach $1.5 \%$ with sharp gradients occurring at transitions to barren surfaces. Systematic biases caused by the neglect of fluorescence in space-based retrievals of $X_{\mathrm{CO}_{2}}$ will thus resemble these regional-scale spatial structures, which, in turn, are related to GPP.

\section{Fluorescence implementation in simulations and retrievals}

From a radiative transfer perspective, chlorophyll fluorescence can be considered as a spectrally smooth source term at the surface. As will be explained in the following, we implemented the chlorophyll fluorescence term directly in the radiative transfer solver in forward model simulations. However, we ignore scattering (but not absorption) effects on the fluorescence source term in the implementation in the retrieval scheme, greatly simplifying its parameterization. 


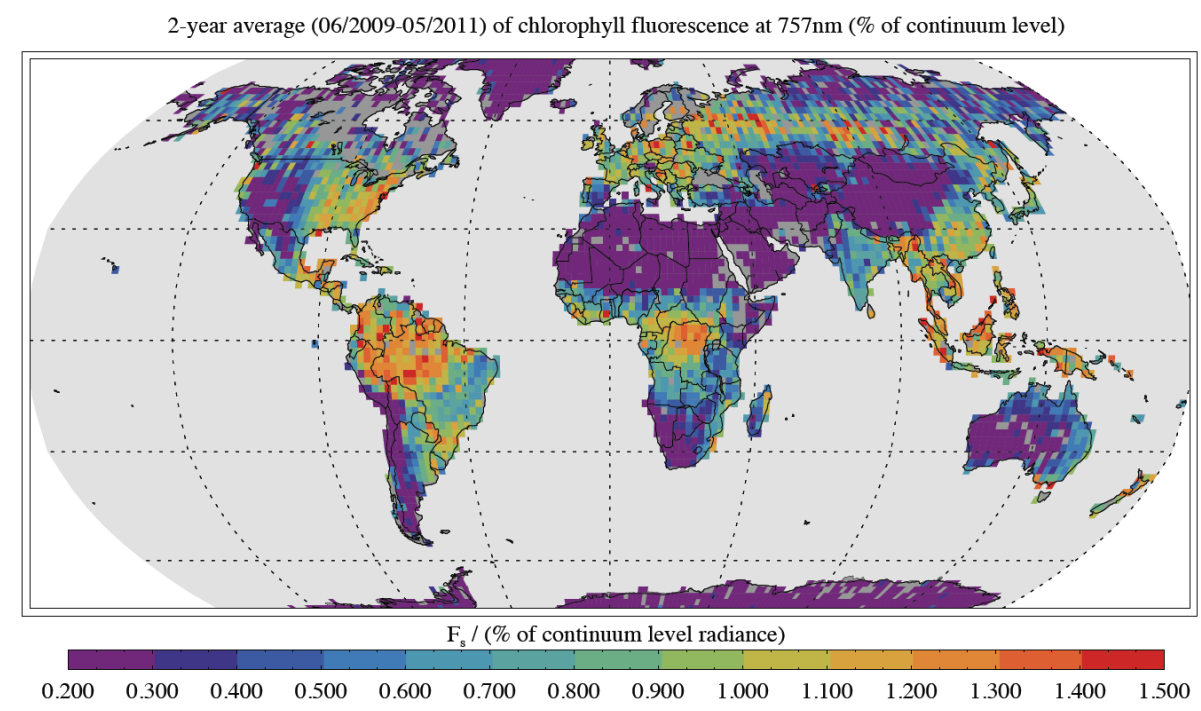

Fig. 1. 2-yr average of retrieved chlorophyll fluorescence at $757 \mathrm{~nm}$, retrieved and corrected according to Frankenberg et al. (2011b).

\subsection{Accurate implementation in a radiative transfer scheme for simulation purposes}

In order to provide realistic simulations of the $\mathrm{O}_{2}$ A-band at TOA impacted by fluorescence, we implemented the hitherto neglected chlorophyll emission into the satellite simulator used for GOSAT and OCO-2 studies (O’Dell et al., 2011). The simulator models spectra at the TOA using realistic and diverse aerosol and cloud distributions, surface and instrument properties, coupled with an accurate radiative transfer model (O'Brien et al., 2009). The main purpose of the simulator is to quantify systematic errors in retrieved $X_{\mathrm{CO}_{2}}$, as the retrieval approach cannot capture the full variability of atmospheric and surface properties, most importantly clouds and aerosols.

For the sake of simplicity, we model fluorescence as an isotropic, unpolarized source term at the surface. The spectral shape of the surface emission, given for instance in Guanter et al. (2010), is modeled as two co-added Gaussians:

$F_{\mathrm{s}}(\lambda)=F_{\mathrm{s}, 755} \cdot\left(A_{1} e^{\frac{-\left(\lambda-\lambda_{1}\right)^{2}}{2 \sigma_{1}^{2}}}+A_{2} e^{\frac{-\left(\lambda-\lambda_{2}\right)^{2}}{2 \sigma_{2}^{2}}}\right)$,

where $F_{\mathrm{s}, 755}$ is the fluorescence intensity at $755 \mathrm{~nm}$. The parameters in Eq. (1) are given in Table 1.

This model has the benefit that it enables future studies using other wavelength regions and that the spectral shape in the A-band is fairly realistic. This allows for the assessment of errors due to the assumption of linearity used in the retrieval described in Sect. 3.2.

The fluorescence emission from the surface has to pass through the atmosphere to be detected by the satellite at TOA. It will undergo absorption by gases, Rayleigh scattering, as well as possible extinction by clouds and aerosols.
These effects are accurately modeled using a 24-stream adding-doubling radiative transfer model (see, e.g., Liou, 2002). In this radiative transfer approach, global scalar reflectance and transmittance matrices are derived for the entire atmosphere using doubling for individual layers, and adding in order to combine all the atmospheric layers together. The surface emission at TOA is modeled as:

$\boldsymbol{F}_{\mathrm{TOA}}=\mathbf{T}_{\mathrm{a}}\left(\mathbf{I}-\mathbf{R}_{\mathrm{g}} \mathbf{R}_{\mathrm{a}}\right)^{-1} \boldsymbol{F}_{\text {surf }}$,

where $\mathbf{T}_{\mathrm{a}}\left(\mathbf{R}_{\mathrm{a}}\right)$ is the atmospheric transmittance (reflectance) matrix from surface to space, $\mathbf{R}_{\mathrm{g}}$ is the surface reflectance matrix, $\boldsymbol{F}_{\text {surf }}$ is the isotropic fluorescence emission vector at the surface, and $\boldsymbol{F}_{\mathrm{TOA}}$ is the corresponding vector at TOA. Polarization effects of the atmosphere on the unpolarized fluorescence emission are assumed to be small. As for the scattered solar irradiance, the method of "lowstreams interpolation" (O'Dell, 2010) is used to accelerate the radiative transfer.

The spatial distribution of $F_{\mathrm{s}}$ in the simulator is based upon $0.5^{\circ} \times 0.5^{\circ} \mathrm{GPP}$ distribution from Beer et al. (2010) and the empirical linear relationship between $F_{\mathrm{s}}$ and GPP derived in Frankenberg et al. (2011b). For the following analysis, we simulated three polar orbits of a GOSAT-like instrument in nadir viewing geometry. This is a subset of the orbits used in a recent simulation-based study of satellite-based $X_{\mathrm{CO}_{2}}$ retrievals (O'Dell et al., 2011).

To conclude, we implemented the chorophyll fluorescence emission into an orbit simulator, fully modeling the propagation of the signal through a scattering atmosphere, also including multiple scattering effects. 
Table 1. Parameters of the fluorescence spectral shape model used in simulations.

\begin{tabular}{cccc}
\hline Gaussian & $A\left(\mathrm{~W} \mathrm{~m}^{-2} \mu \mathrm{m}^{-1} \mathrm{sr}^{-1}\right)$ & $\lambda(\mathrm{nm})$ & $\sigma(\mathrm{nm})$ \\
\hline 1 & 1.445 & 736.8 & 21.2 \\
2 & 0.868 & 685.2 & 9.55 \\
\hline
\end{tabular}

\subsection{Simplified implementation for retrieval purposes}

A typical $X_{\mathrm{CO}_{2}}$ full-physics retrieval algorithm uses a radiative transfer model to simulate radiances at TOA as a function of atmospheric parameters such as surface albedo as well as absorption and scattering profiles (including scattering phase functions). The Jacobians of the simulated radiances are computed with respect to retrieval parameters such as the $\mathrm{CO}_{2}$ profile, surface albedo, as well as aerosol optical depth (AOD) and profile. Given a true set of radiances measured by a space-borne spectrometer, the retrieval parameters can be inverted using a non-linear least squares approach minimizing the differences between modeled and measured radiances. The most common setup makes concurrent use of three bands in a combined retrieval: the $\mathrm{O}_{2} \mathrm{~A}$-band at $760 \mathrm{~nm}$ as well as weak and strong $\mathrm{CO}_{2}$ bands at 1.6 and $2 \mu \mathrm{m}$, respectively. Chlorophyll fluorescence, if neglected, will impact the radiances in one of the retrieval windows, viz. the $\mathrm{O}_{2}$ A-band.

We now describe modifications to the standard ACOS/OCO-2 (ACOS = Atmospheric Carbon Observations from Space) $X_{\mathrm{CO}_{2}}$ retrieval algorithm to include chlorophyll fluorescence. This algorithm has been described at length in O'Dell et al. (2011) and references therein. Briefly, this optimal estimation-based algorithm (Rodgers, 2000) attempts to minimize differences between observed and modeled spectra in the three spectral bands described above, moderated by a side constraint involving prior knowledge. The algorithm fits simultaneously for a profile of $\mathrm{CO}_{2}$, surface pressure, a linearly-varying surface albedo in each of the three fitted bands, spectral wavelength offset in each band, and profiles of four scattering particle types with fixed microphysical and optical properties. These include a water cloud type, an ice cloud type, and two different aerosol types. The idea is that by mixing together these different types appropriately, virtually any type of scattering situation can be modeled. When applied to actual GOSAT data, it was found that an additional state vector parameter representing a zero-level offset in the $\mathrm{O}_{2}$ A-band was also needed to correct for an instrument calibration problem (Crisp et al., 2012; Butz et al., 2011).

We implemented the chlorophyll fluorescence emission as two additional state vector elements in the ACOS retrieval algorithm, as follows. We simplify the simulation of the chlorophyll emission inside the retrieval forward model by decoupling it entirely from the radiative transfer mode.
Instead of calculating the full scattering effect on the chlorophyll emission observed at TOA, we solely model the spectral shape as well as the absorption features by $\mathrm{O}_{2}$. The fluorescence is then treated as a simple additive term to the radiance calculated by the radiative transfer code before convolution with the instrument line shape is performed. The fluorescence term at the surface (using $\mathrm{nm}$ as $\lambda$ units) in the retrieval is:

$F_{\mathrm{s}}(\lambda)^{\mathrm{surf}}=F_{\mathrm{s}, 755}^{\mathrm{surf}} \cdot(1-s(\lambda-755))$,

where the two state vector elements $F_{\mathrm{s}, 755}$ and $s$ represent the chlorophyll emission at $755 \mathrm{~nm}$ and its spectral slope, respectively. Compared to a simpler polynomial representation of $F_{\mathrm{S}}(\lambda)^{\mathrm{surf}}$, this parameterization allows a scaling of a predefined spectral shape with some freedom for adjusting the slope itself. This model explicitly assumes a linear spectral shape over the relatively narrow $\mathrm{O}_{2}$ A-band, an assumption that is not made in the $F_{\mathrm{S}}$ simulation (Sect. 3.1).

At TOA, the modeled fluorescence ignoring scattering reads:

$F_{\mathrm{S}}(\lambda)^{\mathrm{TOA}} \approx F_{\mathrm{s}}(\lambda)^{\mathrm{surf}} \cdot e^{-\tau_{\mathrm{O}_{2}}(\lambda) / \mu}$,

where $\mu$ represents the cosine of the viewing zenith angle and $\tau_{\mathrm{O}_{2}}(\lambda)$ the vertical optical thickness of $\mathrm{O}_{2} . F_{\mathrm{S}}(\lambda)^{\mathrm{TOA}}$ is simply added to the radiative transfer scheme implemented in the ACOS/OCO-2 full-physics retrieval algorithm, largely facilitating the calculation of Jacobians with respect to $F_{\mathrm{s}, 755}$ and $s$.

\section{Interference errors between scattering properties, $X_{\mathrm{CO}_{2}}$ and chlorophyll fluorescence}

The impact of chlorophyll fluorescence on the retrieval of $X_{\mathrm{CO}_{2}}$ is rather complex, as it is propagated through its interference with retrieved scattering properties and, potentially, surface pressure. The impact can vary not only sceneby-scene but also between different retrieval algorithms, depending on how scattering and surface pressure are treated. However, there always is a propagation of biases from the $\mathrm{O}_{2}$ A-band into $X_{\mathrm{CO}_{2}}$, unless the retrieval is set up to entirely decouple the $\mathrm{O}_{2}$ A-band from the $\mathrm{CO}_{2}$ retrieval, which would forfeit the initial purpose of the $\mathrm{O}_{2} \mathrm{~A}$-band in $\mathrm{CO}_{2}$ retrievals. In this study, we focus on the ACOS/OCO-2 3-band retrieval algorithm described above.

To gain a deeper understanding of the retrieval problem, we perform simulations and retrievals of varying complexity, listed in Table 2. We first focus on the case where fluorescence is entirely ignored in the $X_{\mathrm{CO}_{2}}$ retrieval step. To our knowledge, this is currently the standard approach in all retrievals that utilize the $\mathrm{O}_{2}$ A-band (e.g., Schneising et al., 2008; Butz et al., 2011; Parker et al., 2011; O’Dell et al., 2011; Yoshida et al., 2011), and is thus highly relevant. We then analyze the results of a retrieval with fluorescence included as part of the state vector according to Sect. 3.2. To 
Table 2. Simulation and retrieval setups used in the sensitivity studies. Baseline runs are the benchmark for business as usual (fluorescence neither simulated nor retrieved), runs \#xa have fluorescence in the simulation but ignore them in the retrieval, and runs \#xb attempt to fit fluorescence in the retrieval as well.

\begin{tabular}{|c|c|c|c|c|c|}
\hline \multirow{2}{*}{ Run } & \multicolumn{2}{|c|}{ Simulation } & \multicolumn{3}{|c|}{ Retrieval } \\
\hline & Aerosols & Fluorescence & Aerosols & Fluorescence & Surface pressure \\
\hline Baseline 1 & not incl. & not incl. & not fitted & not fitted & fitted \\
\hline Baseline 2 & incl. & not incl. & fitted & not fitted & fitted \\
\hline Baseline 3 & incl. & not incl. & fitted & not fitted & not fitted \\
\hline$\# 1 \mathrm{a}$ & not incl. & incl. & not fitted & not fitted & fitted \\
\hline$\# 2 \mathrm{a}$ & incl. & incl. & fitted & not fitted & fitted \\
\hline$\# 3 \mathrm{a}$ & incl. & incl. & fitted & not fitted & not fitted \\
\hline$\# 1 \mathrm{~b}$ & not incl. & incl. & not fitted & fitted & fitted \\
\hline$\# 2 b$ & incl. & incl. & fitted & fitted & fitted \\
\hline$\# 3 b$ & incl. & incl. & fitted & fitted & not fitted \\
\hline
\end{tabular}

quantify systematic biases, we run all retrievals twice: once using simulations with no fluorescence added and once with fluorescence included. In the following, all biases caused by fluorescence are reported as the difference between the two runs. Both runs are performed using noise-less simulations, while a realistic GOSAT-like noise is assumed in the measurement error covariance matrix for the retrieval.

\subsection{Case I: ignoring fluorescence}

As stated previously, most retrieval algorithms of $\mathrm{CO}_{2}$ which employ the $\mathrm{O}_{2}$ A-band currently entirely ignore chlorophyll fluorescence. They will thus be subject to systematic biases depending on their specific retrieval setup as well as instrument characteristics, most importantly spectral resolution. Here and in the following, we focus on simulations performed for GOSAT spectral resolution. Contrary to SCIAMACHY, for instance, Fraunhofer lines can be better resolved and will thus reduce interference errors.

\subsubsection{Aerosol-free atmosphere}

In the absence of aerosol scattering in the atmosphere, chlorophyll fluorescence nevertheless impacts the retrieval of $X_{\mathrm{CO}_{2}}$, as the reduction in fractional depth of $\mathrm{O}_{2}$ absorption lines can resemble a change in surface pressure. Case \#1a represents this most simple case, viz. a completely aerosol free atmosphere assumed in both simulations and retrievals. The only free variables in the retrieval related to the $\mathrm{O}_{2}$ Aband are thus spectral albedo, spectral shift, temperature offset and surface pressure (given a $4 \mathrm{hPa} 1-\sigma$ prior uncertainty). As $F_{\mathrm{s}}$ fills in the $\mathrm{O}_{2}$ lines, surface pressure is consequently underestimated with increasing $F_{\mathrm{s}}$.

Figure 3 shows the errors propagating into $\mathrm{CO}_{2}$ via the negative surface pressure bias with increasing fluorescence. At about $1 \%$ relative $F_{\mathrm{s}}$, the overestimation in $X_{\mathrm{CO}_{2}}$ amounts to $1 \mathrm{ppm}$. Changes in retrieved surface pressure are about
$2.5 \mathrm{hPa}$, slightly higher than current uncertainties in surface pressure from meteorological models $(1-2 \mathrm{hPa}$, Salstein et al., 2008). Errors propagated into $X_{\mathrm{CO}_{2}}$ are, in this case, entirely caused by biases in the retrieved dry airmass (through surface pressure) needed to calculate the column averaged dry air mole fraction of $\mathrm{CO}_{2}$.

\subsubsection{Aerosol-laden atmosphere}

In the presence of scattering in the atmosphere (both in simulation and retrieval), the impact on $X_{\mathrm{CO}_{2}}$ is more complex as various fitting parameters for atmospheric aerosols and/or clouds have to be included in the state vector. These parameters have been shown to interfere with fluorescence as well (Frankenberg et al., 2011a). In a scattering atmosphere, postprocessing has to be performed discarding non-converging and bad retrievals according to O'Dell et al. (2011), with a retrieved AOD threshold of $<0.2$.

Figure 4 shows results from case \#2a, where both aerosols as well as surface pressure are free retrieval parameters. As expected, the results are more mixed, with higher scatter in the $X_{\mathrm{CO}_{2}}$ biases. The overall fluorescence-induced bias in $X_{\mathrm{CO}_{2}}$ is somewhat lower than in case \#1a, mainly because aerosols can now partially account for the fluorescence term. The propagation of aerosols biases is, however, not as direct as in the case of surface pressure, thus explaining the smaller $X_{\mathrm{CO}_{2}}$ as well as surface pressure changes. Intuitively, one would expect that retrieved aerosols increase with increasing fluorescence as higher aerosol backscatter typically reduces the absorption depth of $\mathrm{O}_{2}$ lines. However, at high surface albedos, the opposite can also be true as aerosols can also lengthen the light path. This is probably the reason why changes in retrieved aerosol properties are not particularly systematic. Overall, we see an insignificant decrease in retrieved total aerosol optical depth but a significant redistribution of aerosols to higher atmospheric layers, which more 


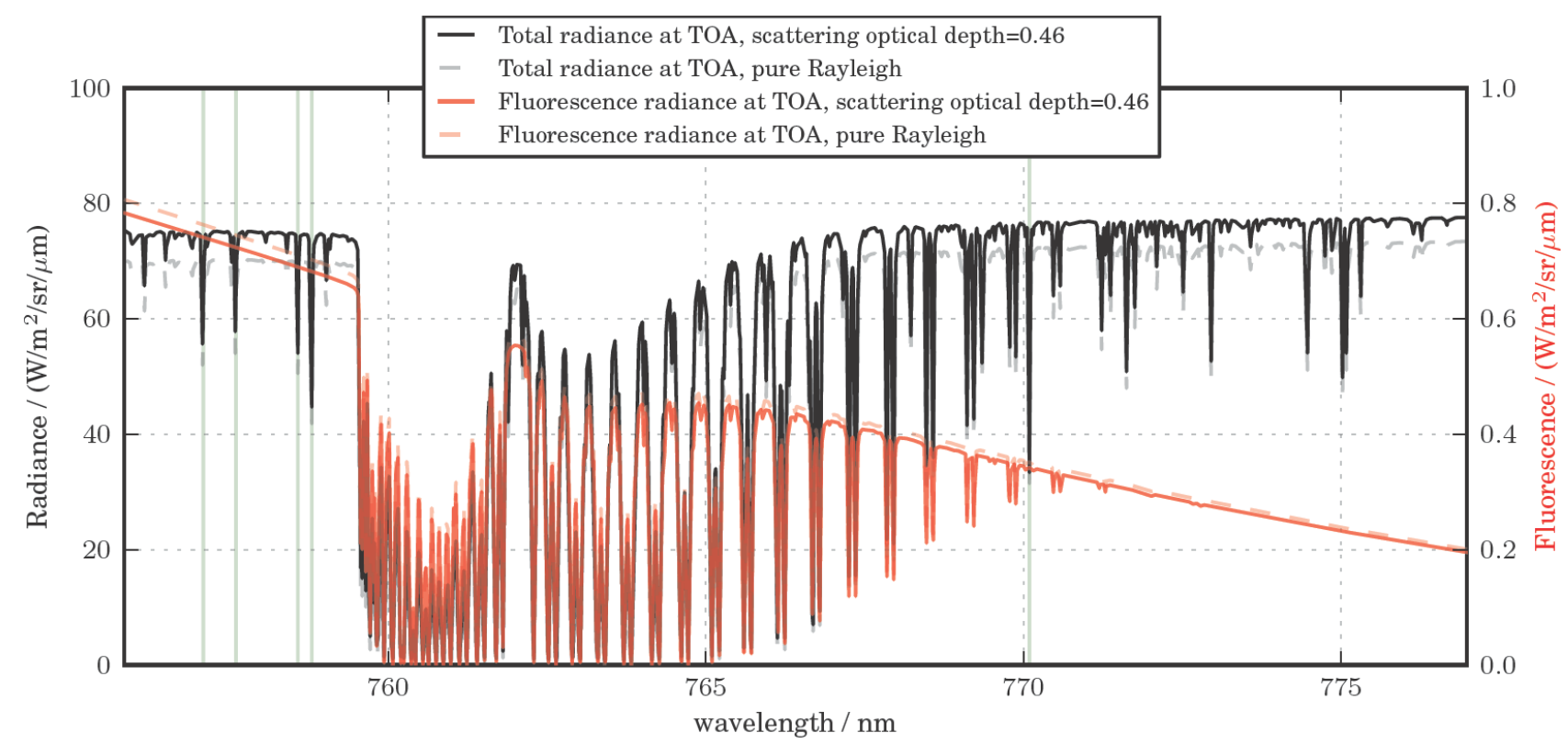

Fig. 2. Simulated noise-free spectrum with GOSAT spectral resolution. Solar zenith angle $=26.35^{\circ}$; surface albedo $\approx 0.2$; aerosol + cloud optical depth $=0.46$. The fluorescence spectrum at the TOA is modeled once in a pure Rayleigh atmosphere and once including aerosol and cloud scattering of the emission emanating from the surface. Positions of Fraunhofer lines most suitable for fluorescence retrievals in the GOSAT spectral range are indicated by green lines.
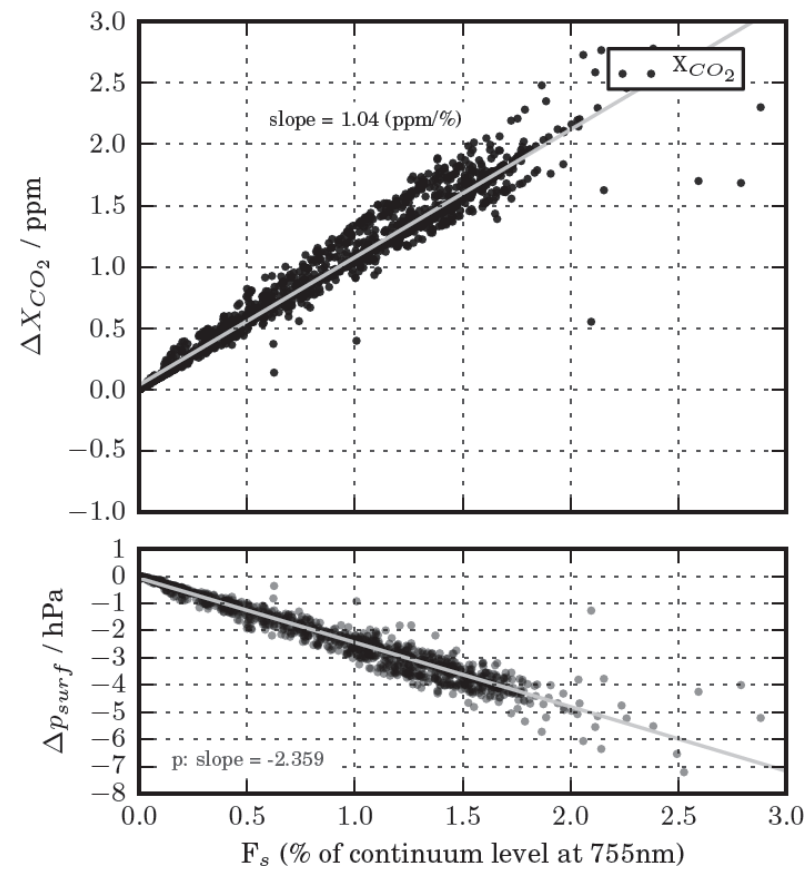

Fig. 3. Case \#1a: Changes in retrieved $X_{\mathrm{CO}_{2}}$ as well as surface pressure induced by chlorophyll fluorescence if it is ignored in the retrieval step. Both simulation and retrieval use a Rayleigh-only atmosphere. efficiently shorten the atmospheric light path (note: in our setup, aerosol height is defined as the peak height of a Gaussian aerosol profile).

To investigate the isolated impact of aerosols, we performed case \#3a, where surface pressure is assumed known, an assumption made by some $\mathrm{CO}_{2}$ retrievals (e.g., Butz et al., 2011). Figure 5 shows these results, where naturally only aerosols as well as $X_{\mathrm{CO}_{2}}$ change systematically. As the error propagation through surface pressure is eliminated, the bias induced in $X_{\mathrm{CO}_{2}}$ is lower, though still apparent with an average slope of $0.55 \mathrm{ppm}$ per $\mathrm{W} \mathrm{m}^{-2} \mathrm{sr}^{-1} \mu \mathrm{m}^{-1}$ of NIR chlorophyll fluorescence. However, in both case \#2a and case \#3a, substantial random scatter in retrieved $X_{\mathrm{CO}_{2}}$ and AOD is induced as well. The impact on aerosols is naturally larger when the surface pressure is fixed.

Looking at cases \#1a-3a, one can conclude that the neglect of fluorescence in our particular retrieval (and instrument characteristics) can result in systematic biases of $\approx$ $0.5-1 \mathrm{ppm}$ per percent fluorescence contribution to the continuum radiance. Biases in retrieved $\mathrm{CO}_{2}$ are thus within $\approx 1.5 \mathrm{ppm}$ but vary frequently in the spatial domain (see Fig. 1). While these biases are still below $1 \%$ of the $\mathrm{CO}_{2}$ column amount, they exhibit spatial and temporal correlations with GPP, which is why they must not be neglected.

\subsection{Case II: fitting fluorescence}

As we have seen in the previous section, fluorescence can cause systematic biases in retrieved $X_{\mathrm{CO}_{2}}$, surface pressure 


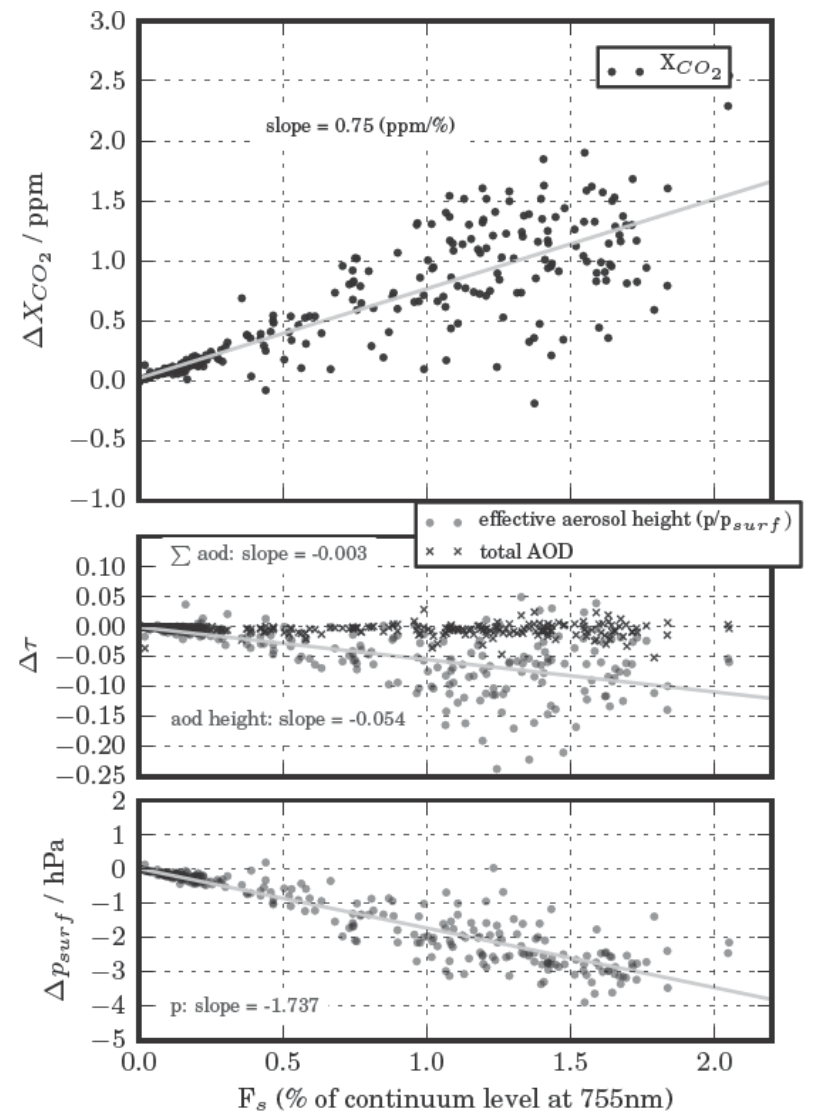

Fig. 4. Case \#2a: Changes in retrieved $X_{\mathrm{CO}_{2}}$, retrieved aerosols as well as surface pressure induced by chlorophyll fluorescence if it is ignored in the retrieval step. Simulations use a complex set of aerosol scenes, and the retrieval employs the ACOS/OCO-2 standard retrieval setup, fitting for aerosols and surface pressure. Effective aerosol height is defined in normalized pressure coordinates (fraction of surface pressure).

and aerosols. As interferences shown in Frankenberg et al. (2011a) point to problems in fitting all variables simultaneously, we investigate the impact of including fluorescence as a state vector element, as described in Sect. 3.2. This is done from the perspective of reducing systematic biases in $X_{\mathrm{CO}_{2}}$, rather than to retrieve fluorescence accurately. Several studies have already fitted fluorescence using GOSAT data (Frankenberg et al., 2011a,b; Joiner et al., 2011, 2012), but these have so far focussed solely on Fraunhofer lines, avoiding telluric $\mathrm{O}_{2}$ absorption features. These are typically used in ground-based studies but are, as will be corroborated in the following section, problematic if observed from TOA.

In the pure Rayleigh case, where aerosols are present neither in the simulations nor in the retrieval, the fit can virtually eliminate the systematic error previously existent in $X_{\mathrm{CO}_{2}}$. As shown in Fig. 6 , the $X_{\mathrm{CO}_{2}}$ bias changes from 1.07 to $0.07 \mathrm{ppm}^{-1}$ compared to case \#1a. Also, fluorescence is fitted quite accurately, with the caveat that these are noise-free simulations. However, the retrieval is not able to

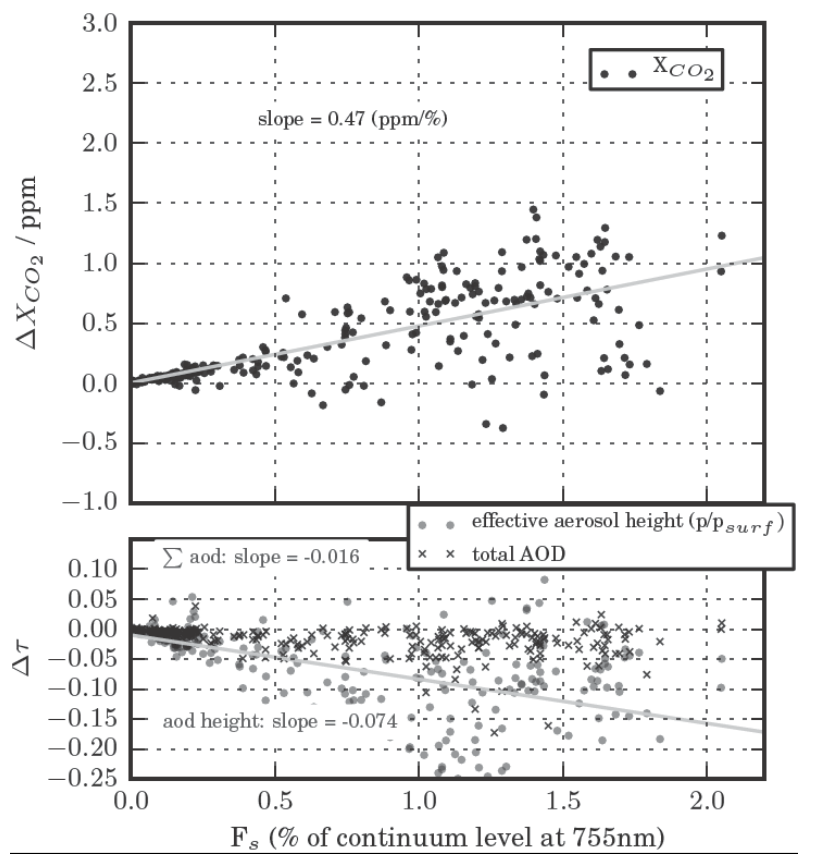

Fig. 5. Case \#3a: Changes in retrieved $X_{\mathrm{CO}_{2}}$ as well as aerosol induced by chlorophyll fluorescence if it is ignored in the retrieval step. Identical to case \#2a, Fig. 4, with the only difference that surface pressure is assumed known in the retrieval, i.e., not fitted.

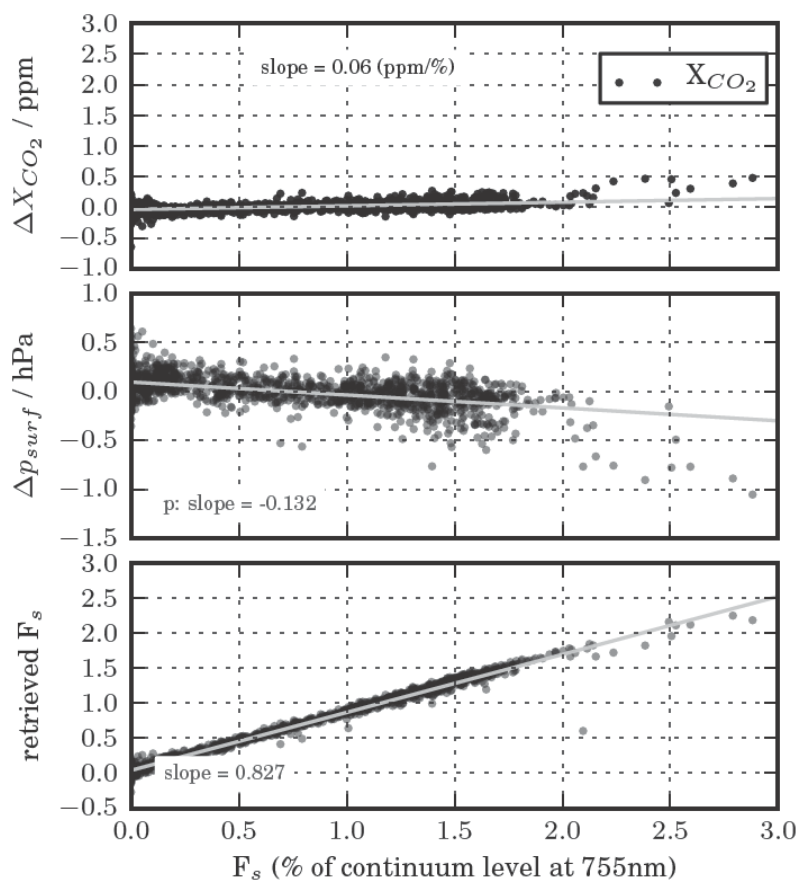

Fig. 6. Case \#1b: Changes in retrieved $X_{\mathrm{CO}_{2}}$ induced by chlorophyll fluorescence if fluorescence is fitted. Both simulation and retrieval use a Rayleigh-only atmosphere. 


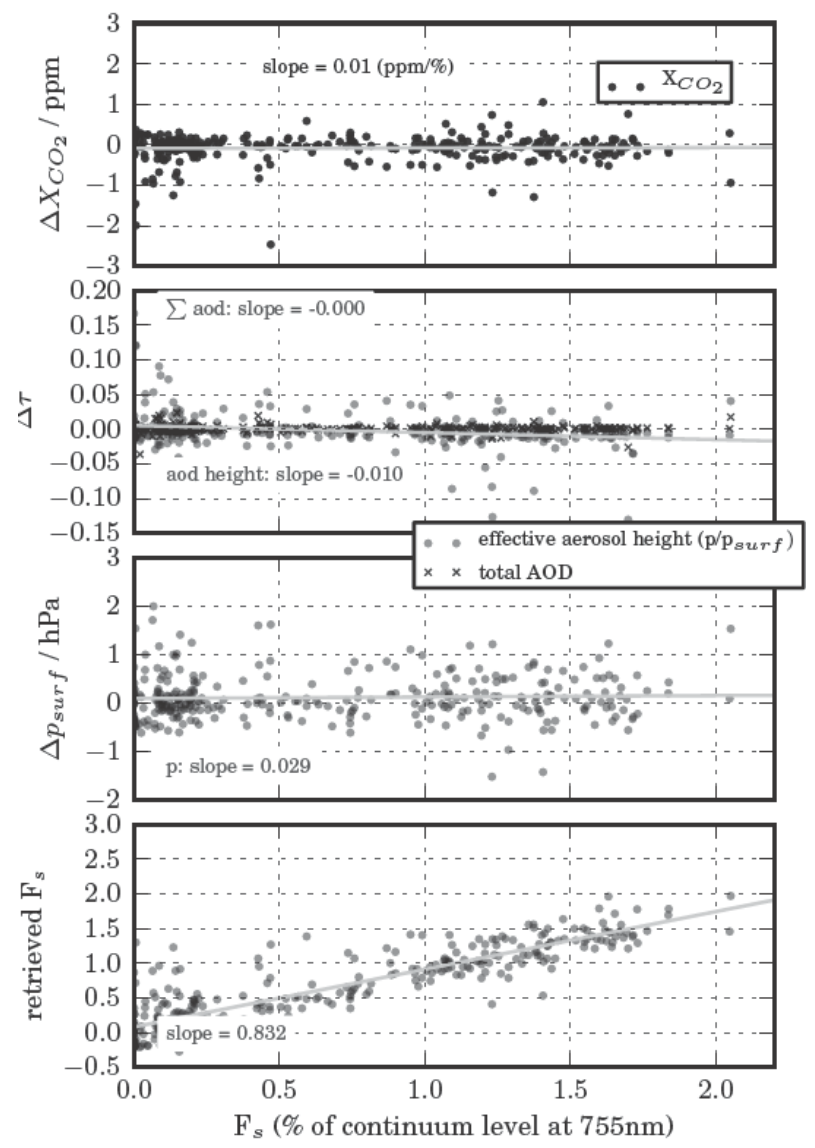

Fig. 7. Case \#2b: Changes in retrieved $X_{\mathrm{CO}_{2}}$ as well as aerosol induced by chlorophyll fluorescence if fluorescence is fitted. Apart from the fluorescence fit, identical to case \#2a, Fig. 4.

reproducethe true fluorescence $1: 1$, potentially because of the neglect of Rayleigh scattering in the retrieval forward modeling of fluorescence.

Results, especially in terms of scatter unrelated to noise, become more complex when aerosols are explicitly included. Figure 7 shows results for case \#2b, where aerosols are present in the simulations, and aerosols as well as surface pressure are fitted in the retrieval. The systematic bias in $X_{\mathrm{CO}_{2}}$ as well as surface pressure is not significant and seems to be dominated by a few outliers. However, there is high scatter in the retrieved fluorescence parameter (noting that this is an accuracy, not a precision error as simulations are noise-free). There is also some scatter induced in $X_{\mathrm{CO}_{2}}$, but most deviations are below $1 \mathrm{ppm}$ and appear unsystematic.

Perfect knowledge of surface pressure (\#3b, Fig. 8) slightly improves the situation, with a slope of close to 1 in retrieved vs. true fluorescence. However, the scatter in retrieved $F_{\mathrm{s}}$ in case \#3b is still very high, but systematic biases in $X_{\mathrm{CO}_{2}}$ as a function of signal level are small. The inclusion of fluorescence as fitting parameters caused some outliers in retrieved $X_{\mathrm{CO}_{2}}$ at low true $F_{\mathrm{s}}$ values though.

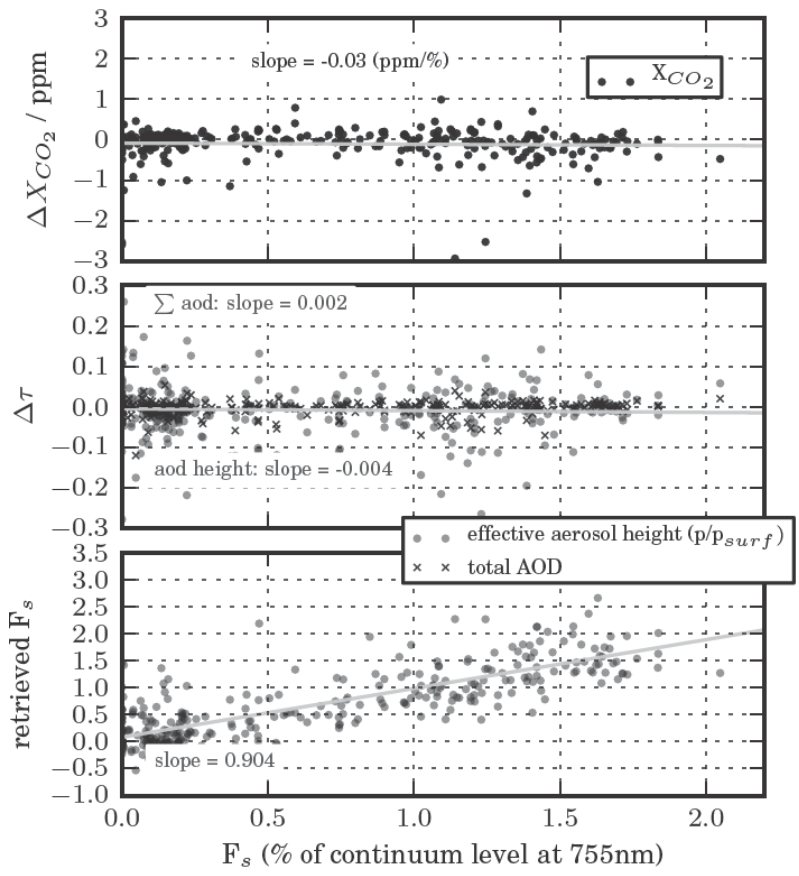

Fig. 8. Case \#3b: Changes in retrieved $X_{\mathrm{CO}_{2}}$ as well as aerosol induced by chlorophyll fluorescence if fluorescence is fitted. Apart from the fluorescence fit, identical to case \#3a, Fig. 5.

In summary, the results confirm what has been alluded to in Frankenberg et al. (2011a): (a) there is a strong but hard to generalize interference between fluorescence, surface pressure and aerosol properties, and (b) if ignored, systematic biases in $X_{\mathrm{CO}_{2}}$ on the order of $1 \mathrm{ppm}$ can occur. Inclusion of fluorescence as a state vector element partially eliminates the bias but is not ideal if chlorophyll fluorescence itself is the target quantity. Using the potentially added information contained in the $\mathrm{O}_{2}$ absorption structures seems to do more harm than good for the fluorescence retrieval because interferences are introduced. If the retrieval from space would be purely based on the $\mathrm{O}_{2}$ A-band (as is done frequently in groundbased studies), ancillary information on aerosols from other sensors thus will not necessarily be accurate enough to provide a useful constraint, as the impact on the $\mathrm{O}_{2}$ lines is a complex function of AOD, aerosol type, height and surface albedo. The fact that we did not see very systematic changes in retrieved aerosol parameters when ignoring fluorescence supports this conclusion. Similar concerns would be valid for airborne studies, if aerosol scattering between the surface and flight altitude exists. A combination of $\mathrm{O}_{2}$ A- and B-bands, such as envisioned in the FLEX mission concept, would be preferred if spectral resolution is not high enough to exploit Fraunhofer line features (Guanter et al., 2010; Sanghavi et al., 2012). 


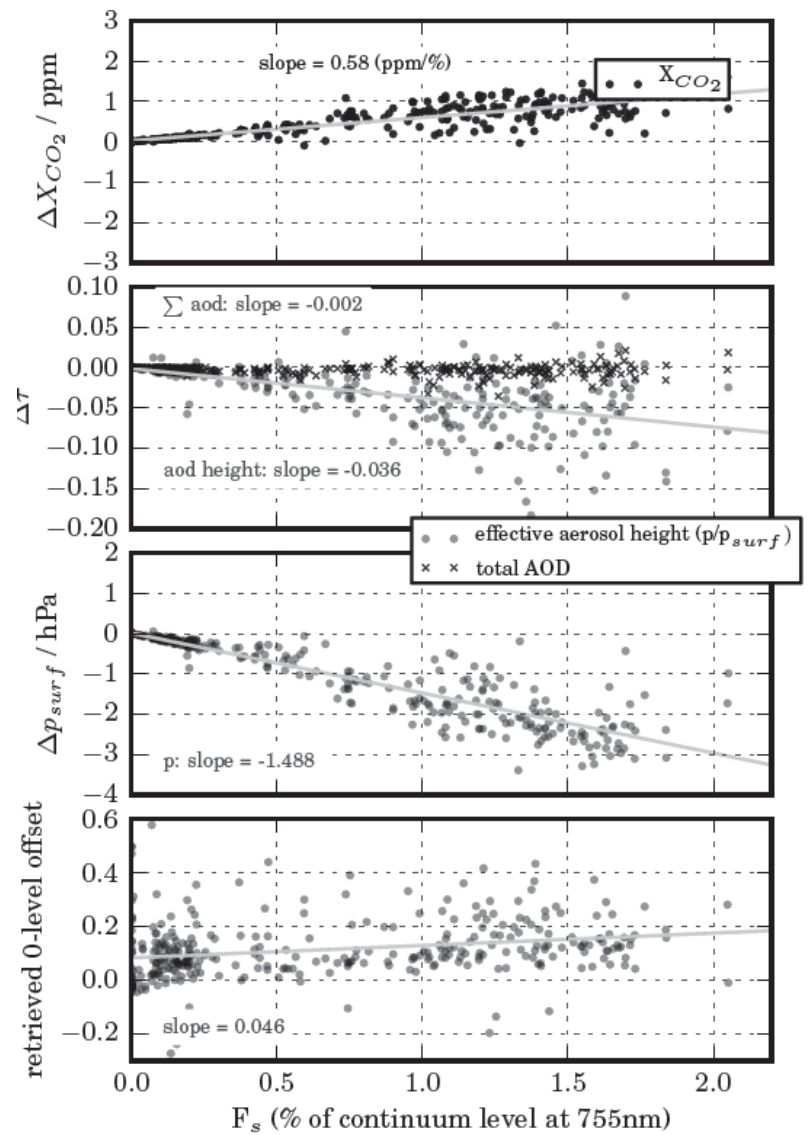

Fig. 9. Changes in retrieved $X_{\mathrm{CO}_{2}}$ as well as aerosol induced by chlorophyll fluorescence if it is ignored in the retrieval step but zerolevel offset fitted. Otherwise, identical to case \#2a, Fig. 4.

\subsection{Implications for GOSAT retrievals considering the A-band zero-level offset}

Frankenberg et al. (2011b) discovered a zero-level offset in GOSAT $\mathrm{O}_{2}$ A-band spectra, which was subsequently confirmed by an independent analysis of the JAXA GOSAT team. This adds another dimension to the problem for this particular case for a zero-level offset in FTS systems causes a rather flat offset to the true radiance at all wavelengths. For Fraunhofer lines, this effect is thus virtually indistinguishable from a chlorophyll fluorescence signal as both simply add an additive term to the spectrum. Within $\mathrm{O}_{2}$ lines, however, the effect is different from fluorescence for it adds a spectrally flat offset as opposed to fluorescence, where the spectrally flat emission at the surface level is partially reabsorbed by $\mathrm{O}_{2}$ absorption along the path to the detector. Hence, both signals have an identical impact in Fraunhofer lines and the continuum but differ in $\mathrm{O}_{2}$ absorption features.

For previous dedicated fluorescence retrievals using Fraunhofer lines, the zero-level offset contribution was parameterized as a function of average signal level (representative for the zero-path difference readout in FTS systems) and

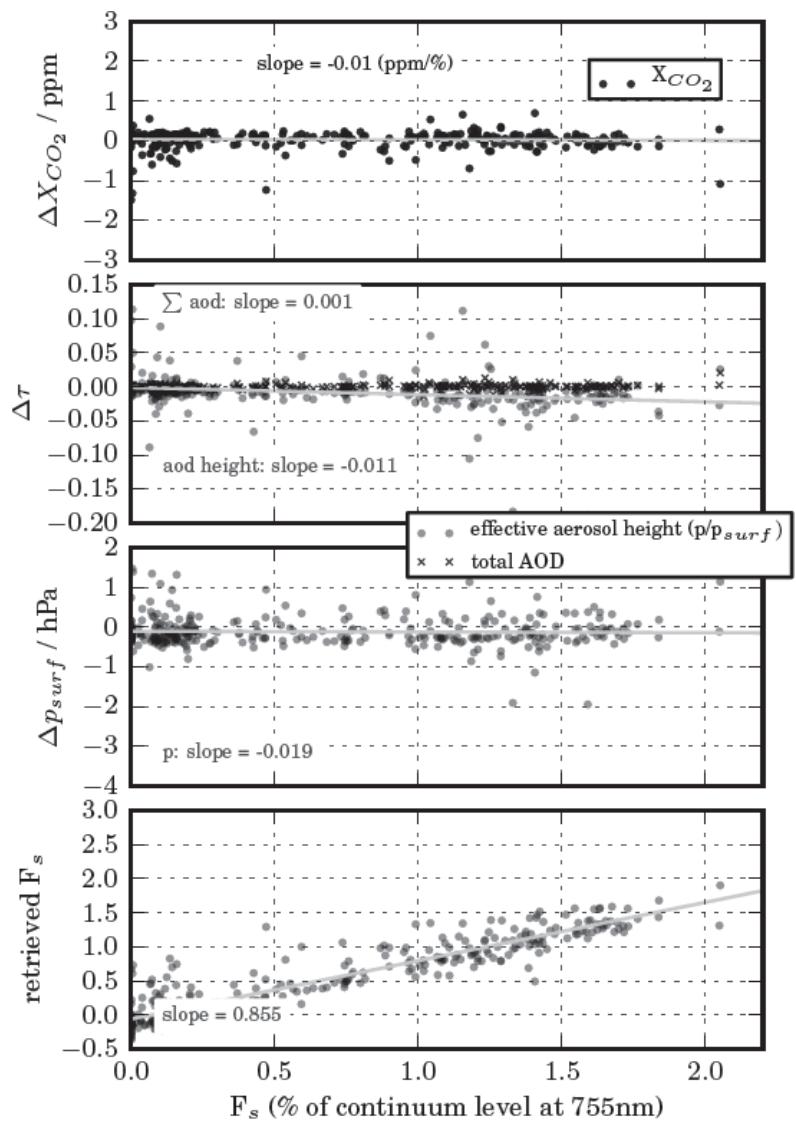

Fig. 10. Changes in retrieved $X_{\mathrm{CO}_{2}}$ as well as aerosol induced by chlorophyll fluorescence if it is fitted in the retrieval step in addition to a zero-level offset fit (similar to the current ACOS retrievals) (O'Dell et al., 2011). Otherwise, identical to case \#2b, Fig. 7.

later subtracted from the retrieved offset in order to isolate the fluorescence term (Frankenberg et al., 2011b; Guanter et al., 2012). Here, we investigate the impact of fluorescence on the full-physics retrieval in view of the apparent zero-level offset. There are two questions to be answered: (a) what is the potential bias induced by fluorescence on current operational $\mathrm{CO}_{2}$ retrievals fitting the zero-level offset but not fluorescence, and (b) will a simultaneous retrieval of fluorescence and zero-level offset be stable and also minimize biases in $X_{\mathrm{CO}_{2}}$ ? For this purpose, we ran two additional tests, where we (a) mimicked the current ACOS operational retrieval by fitting aerosols, surface pressure and zero-level offset but not fluorescence and (b) fitted fluorescence in addition.

Figure 9 shows case (a), where we fit for zero-level offset but ignore fluorescence. As expected, fitting the zero-level offset somewhat diminishes the bias in $X_{\mathrm{CO}_{2}}$, with a slope reduced from 0.86 to $0.58 \mathrm{ppm} \%^{-1}$. However, the bias is still positive and not eliminated as in the case of fitting fluorescence. It can be concluded that a remaining small bias exists in most current $X_{\mathrm{CO}_{2}}$ retrievals. 


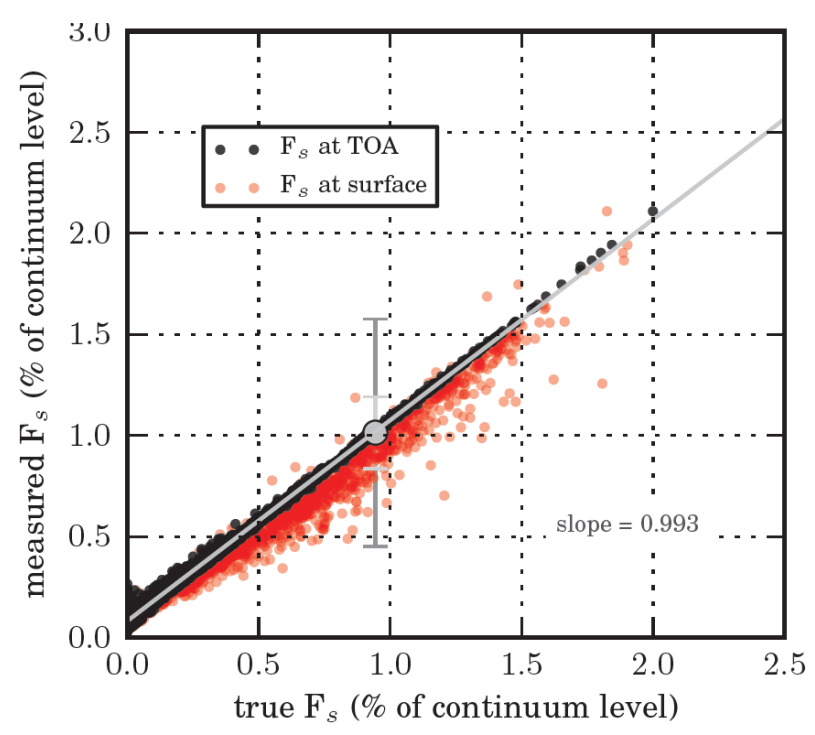

Fig. 11. Retrievals of $F_{\mathrm{S}}$ in a scattering atmosphere using the Fraunhofer line method (Frankenberg et al., 2011a). Points are for true $F_{\mathrm{S}}$ at TOA vs. retrieved $F_{\mathrm{S}}$ (black) and true $F_{\mathrm{S}}$ at the surface vs. retrieved $F_{\mathrm{S}}$ (red). Small deviations from the 1.0 slope can be explained by small differences in the spectral shift and squeeze as well as the assumed constancy of $F_{\mathrm{S}}$ (Frankenberg et al., 2011a). Error-bars indicate a typical $1-\sigma$ precision error for a GOSAT specific retrieval. Dark gray indicates the single measurement noise and light gray the standard error in an average of 10 soundings.

Figure 10 shows case (b) where we fit for both fluorescence and zero-level offset. The retrieval appears as stable as when zero-level offset is not fitted and also the bias in $X_{\mathrm{CO}_{2}}$ is diminished. It can be concluded that current $X_{\mathrm{CO}_{2}}$ retrievals can include both fluorescence and zero-level offset in their retrieval, thereby eliminating the bias through fluorescence even in the presence of systematic instrument errors. The main reason why the fit can partially disentangle fluorescence from zero-level offset is the strong difference in the impact on deeply saturated $\mathrm{O}_{2}$ lines (where zero-level offset has the highest fractional impact but fluorescence is almost entirely reabsorbed in the atmosphere).

\section{Chlorophyll fluorescence as primary retrieval target}

In the previous section, we largely focussed on the impact of fluorescence on $X_{\mathrm{CO}_{2}}$ retrievals. Here, we focus on the implications of atmospheric scattering by clouds and aerosols on the fluorescence retrieval itself. The most appropriate way to deal with fluorescence is to avoid the interferences altogether by allowing for a processing step using Fraunhofer lines only, as in Frankenberg et al. (2011a). In the following, this method is used for fluorescence retrievals as the primary target.

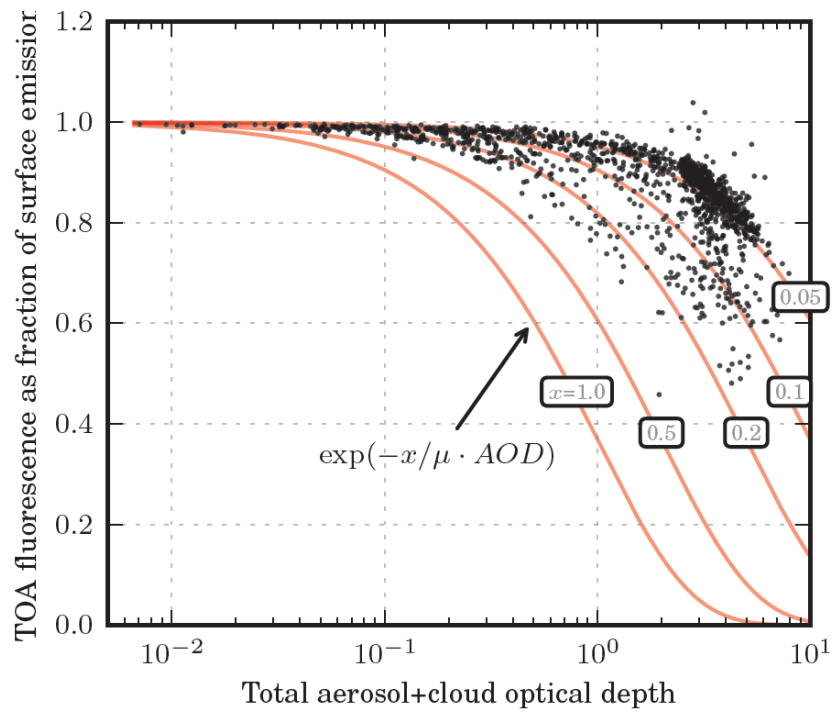

Fig. 12. Fraction of the surface fluorescence emission observed at $755 \mathrm{~nm}$ at the top-of-atmosphere (TOA) as a function of total optical depth (calculated from the simulated fluorescence signal at TOA propagated through the scattering atmosphere). The dots indicate simulated measurements using realistic aerosols and cloud scenarios. The red lines indicate theoretical curves assuming a simple $\exp (-x / \mu \cdot \mathrm{AOD})$ relationship where $x$ takes values of $1,0.5$, $0.2,0.1,0.05$ (curves left to right).

\subsection{Implications of scattering on retrieved chlorophyll fluorescence at top-of-atmosphere}

We have shown previously (Frankenberg et al., 2011a) that pure retrieval interference errors between fluorescence and scattering properties can be eliminated in the retrieval if only Fraunhofer lines are used. In the retrieval as outlined before and also in the Fraunhofer line focussed retrieval, we ignore atmospheric scattering. Hence, the retrieved fluorescence signal accurately represents the true signal at TOA (see Fig. 11) but not necessarily the surface emission.

However, scattering impacts the propagation of the fluorescence emission from the surface to TOA, hence TOA fluorescence does not necessarily represent fluorescence at the plant level. Given an extinction optical thickness of $\tau$, which includes gas absorption, Rayleigh scattering and extinction by clouds and aerosols, the direct beam fluorescence would be reduced by $e^{-\tau / \mu}$. However, the fluorescence signal is partially conserved in the diffuse radiation field. This essentially smears out the effective FOV representative for the $F_{\mathrm{S}}$ signal at TOA, which should be negligible for footprint sizes on the order of multiple kilometers.

To quantify the potential reduction in fluorescence at TOA, we computed the fraction of fluorescence at TOA vs. surface. Figure 12 depicts this fraction using the simulator runs, which employed a nadir observation angle $(\mu=1)$. Please note that this only holds outside of atmospheric absorption bands, i.e., only if the Fraunhofer line method is applied. At 
low optical depths, the ratio is basically 1. Most importantly, the ratio is still well above 0.8 for $\tau<1$ and mostly above 0.6 for $\tau=2-8$. The overall shape of the simulated fractions mostly resembles a $e^{-x \cdot \tau / \mu}$ curve with $x \sim 0.05$. As long as severely absorbing aerosols are absent, a large fraction of the surface fluorescence source is thus conserved in the diffuse radiation field and still contributes to the TOA radiance. We therefore conclude that chlorophyll fluorescence retrievals based on the Fraunhofer line method are hardly susceptible to atmospheric aerosols. In the future, chlorophyll fluorescence remote sensing may even allow for the quantification of photosynthesis in the presence of clouds, a parameter hitherto entirely inaccessible from space and impossible to achieve using reflectance-based retrievals.

The impact of atmospheric extinction between the surface and the TOA on $F_{\mathrm{S}}$ retrieval has been further analyzed with real GOSAT $F_{\mathrm{S}}$ retrievals and AOD data from the AErosol RObotic NETwork (AERONET) (Holben et al., 1998). Temporal series of $F_{\mathrm{S}}$ with and without the compensation of atmospheric transmittance have been produced. The aim of this exercise is to evaluate the error in monthly averages of $F_{\mathrm{S}}$ due to not accounting for atmospheric extinction between the TOA and the top-of-canopy (TOC) levels. TOA $F_{\mathrm{s}}$ retrievals between June 2009 and March 2011 have been generated with the method described in Guanter et al. (2012). AERONET level 2.0 data (cloud-screened and quality assured) are used. Since we were only interested in an estimate of the impact of realistic AOD levels on the retrieval of $F_{\mathrm{s}}$, one year of AOD values have been replicated to cover the entire 22 months of the $F_{\mathrm{S}}$ series.

Temporal series of GOSAT-based $F_{\mathrm{S}}$ retrievals have been extracted from $4^{\circ} \times 4^{\circ}$ boxes centered at different AERONET stations. The atmospheric transmittance associated with each of the single $F_{\mathrm{S}}$ retrievals in the temporal series has been estimated with a look-up table providing total atmospheric transmittance (Rayleigh plus aerosol, both direct and diffuse radiation fields) as a function of the AOD at $550 \mathrm{~nm}$ from AERONET observations. A rural aerosol model has been assumed for these simulations. Monthly averages are then calculated from both the TOA and the atmosphericallycorrected $F_{\mathrm{S}}$ series.

Results for three different areas are shown in Fig. 13. The top panel corresponds to the Ilorin station in Central Africa $\left(8^{\circ} \mathrm{N}, 4^{\circ} \mathrm{E}\right)$, which is the site for which the highest AOD values were found. High AOD events in this area are associated to wildfires happening over the dry season. It can be stated that the impact of those high aerosol loadings in the $F_{\mathrm{S}}$ temporal series is relatively small, with differences in the $F_{\mathrm{s}}$ monthly averages being normally below $0.1 \mathrm{~mW} \mathrm{~m}^{-2} \mathrm{sr}^{-1} \mathrm{~nm}^{-1}$. There seems to be a very low seasonality in the difference between the TOA and the TOC $F_{\mathrm{s}}$, whereas there are strong seasonal signals in both $F_{\mathrm{S}}$ and AOD. This is due to the fact that atmospheric extinction is a multiplicative error source on $F_{\mathrm{s}}$, which makes the seasonality of $F_{\mathrm{S}}$ and AOD tend to cancel each other. The
Central Africa, $8^{\circ} \mathrm{N}, 4^{\circ} \mathrm{E}$, (Aeronet Ilorin)
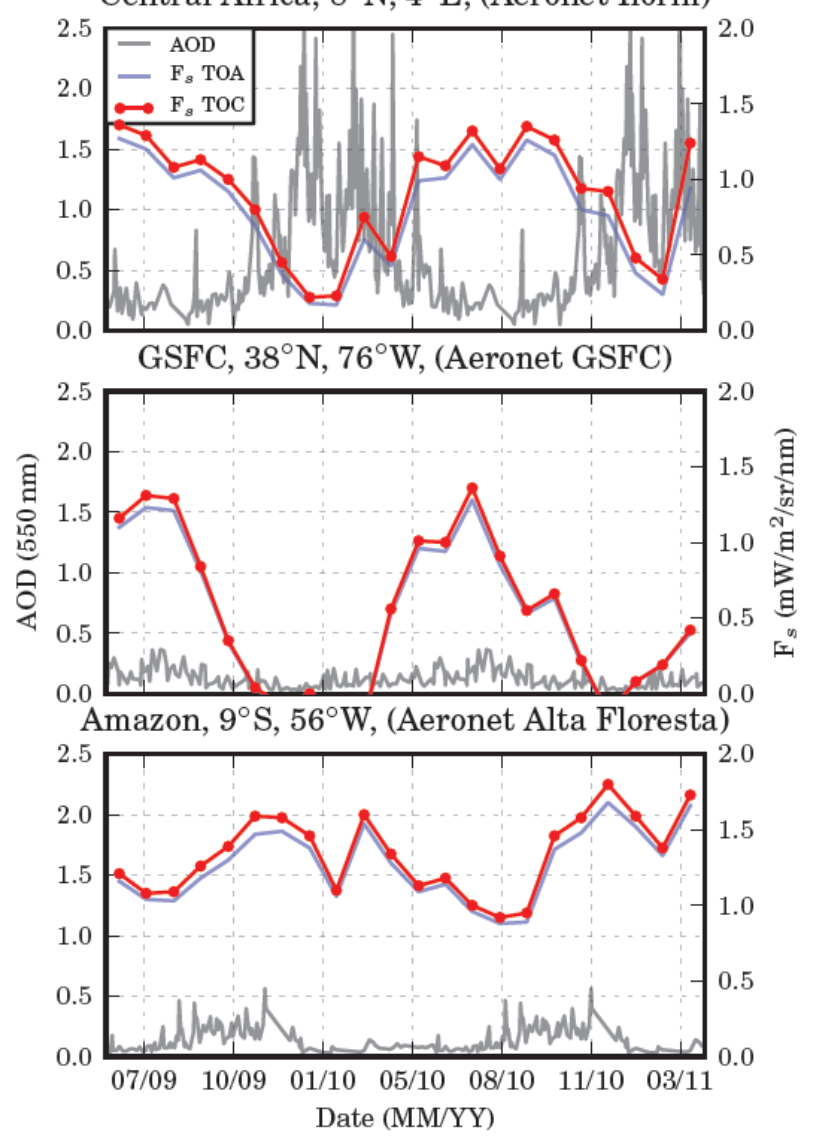

Fig. 13. Temporal series of top-of-atmosphere (TOA) fluorescence and the subsequent top-of-canopy (TOC) fluorescence after compensation of atmospheric extinction (scattering + absorption) for locations in Central Africa (top), Greenbelt, MD (middle) and the Amazon (bottom).

results from another site in the East coast of North America are displayed in the middle panel. AOD values within the year are much lower in this case, with few days having AOD $>0.3$. In absolute terms, significant impacts on $F_{\mathrm{s}}$ are only found for high $F_{\mathrm{S}}$ values due to the multiplicative impact of atmopheric scattering discussed above. The maximum relative errors are around $8 \%$. The same patterns are observed for the Amazon site in the lower panel. The highest relative errors remain below $10 \%$ for the highest AOD values around 0.4 .

\subsection{Potential for future instruments}

While the retrieval method used in Frankenberg et al. (2011a), Joiner et al. (2011), Frankenberg et al. (2011b), and Joiner et al. (2012) is accurate and not very sensitive to atmospheric interferences, it suffers from low precision as instrument noise, in combination with the small signal, results in relatively high 1- $\sigma$ single measurement noise for NIR $F_{\mathrm{s}}$, on the order of $0.5 \mathrm{~W} \mathrm{~m}^{-2} \mathrm{sr}^{-1} \mu \mathrm{m}^{-1}$ for a retrieval 


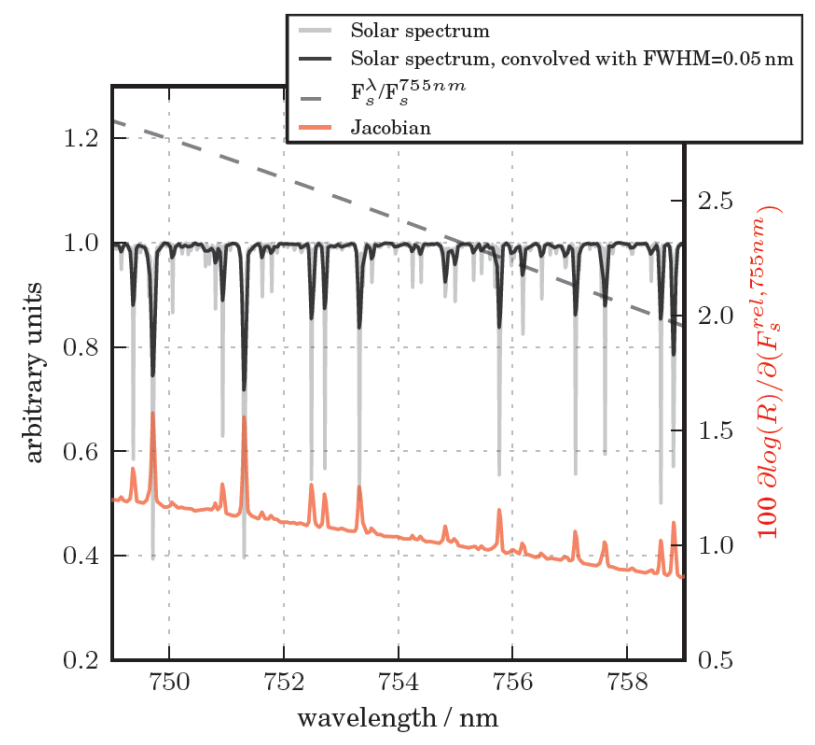

Fig. 14. Potential for fluorescence retrievals in the $749-759 \mathrm{~nm}$ range with an imaginary instrument (spectral resolution of $0.05 \mathrm{~nm}$ FWHM - FWHM = Full Width at Half Maximum). The gray and black solid lines show the solar transmission spectrum at natural and $0.05 \mathrm{~nm}$ FWHM spectral resolution, respectively. The dashed line depicts the spectral shape of a typical fluorescence spectrum (normalized to $755 \mathrm{~nm}$ ). The red line (right axis) shows the derivative of the logarithm of the measured radiance with respect to a change in $F_{\mathrm{S}}$ (defined as change in percent of continuum level radiance at $755 \mathrm{~nm}$, equivalent to $F_{\mathrm{s}}^{\text {rel }}$ in Frankenberg et al., 2011a).

in a single spectral window (see error-bars in Fig. 11). However, current instruments were not designed to retrieve fluorescence, thus the fitting ranges in Frankenberg et al. (2011a), Joiner et al. (2011), Frankenberg et al. (2011b), and Joiner et al. (2012) are chosen out of necessity, limited by the spectral coverage of the respective instrument. Relatively small changes to the GOSAT and OCO-2 instrument design, however, could largely improve retrieval precision: (I) the fluorescence signal strongly increases towards shorter wavelength, peaking at about $740 \mathrm{~nm}$ (see Guanter et al., 2010); (II) there are numerous isolated and strong Fraunhofer lines in the range between $740-760 \mathrm{~nm}$. The GOSAT chlorophyll fluorescence retrievals, for instance, typically exhibit a 1$\sigma$ single sounding precision error of $0.5 \%$ of the continuum level radiance (on the order of $\pm 0.5 \mathrm{~W} \mathrm{~m}^{-2} \mathrm{sr}^{-1} \mu \mathrm{m}^{-1}$ at $755 \mathrm{~nm}$ in absolute flux terms for standard scenarios). Precision errors for OCO-2 are expected to be of similar magnitude, potentially somewhat smaller (see Frankenberg et al., 2011a).

A hypothetical instrument covering the larger spectral range from $749-760 \mathrm{~nm}$, for instance, could still measure the $\mathrm{O}_{2}$ A-band but provide a largely improved chlorophyll fluorescence retrieval, which would not only help improve the fluorescence for its own sake but also result in an improved scattering properties retrieval as the chlorophyll fluorescence

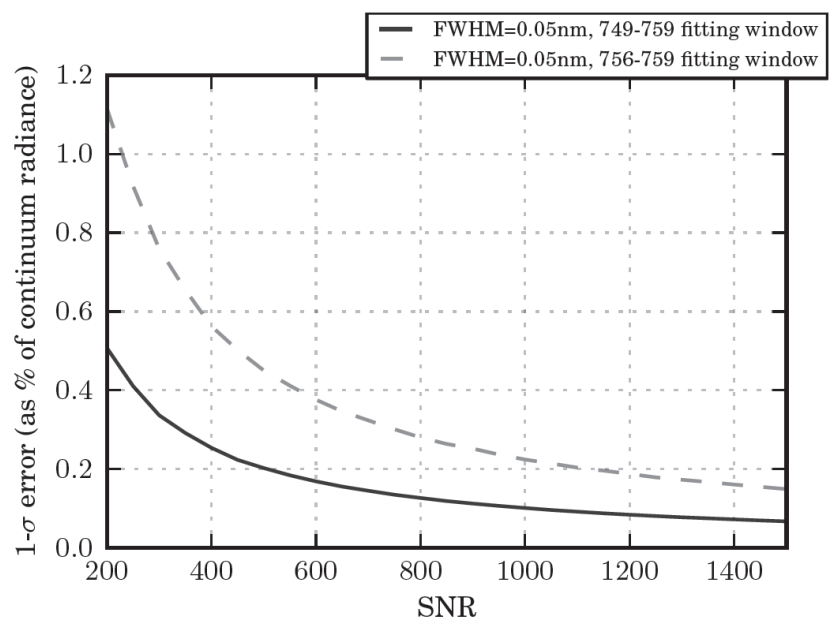

Fig. 15. Single measurement precision error for an imaginary spectrometer with $0.05 \mathrm{~nm}$ FWHM spectral resolution, varying signalto-noise ratio (SNR) and spectra fitting windows for fluorescence.

term is better constrained. We repeated the sensitivity analysis in Frankenberg et al. (2011a) but with an extended spectral range and taking the spectral shape of the fluorescence into account (all errors are normalized to $F_{\mathrm{s}}$ at 755).

Figure 15 shows expected instrument performance using the extended fitting range and $0.05 \mathrm{~nm}$ spectral resolution (full width at half maximum). At $\mathrm{SNR}=1000$, the single measurement noise error is only $0.1 \%$ of the continuum radiance, 5 times lower than for a typical GOSAT sounding (with lower SNR and spectral range but higher spectral resolution). This implies that 25 GOSAT retrievals would be needed to achieve the same standard error (or about 6 for an SNR of 500). At this level of precision, single soundings will become useful individually, as even relatively small changes in fluorescence could be distinguished. Hence, a more dedicated chlorophyll fluorescence measurement purely based on Fraunhofer (not oxygen) line retrievals is feasible with adequate instrumentation because the precision error is not intrinsically high but can be largely reduced by a proper (and realistic) choice of wavelength ranges, spectral resolution and SNR.

\section{Conclusions}

We have quantified the impact of chlorophyll fluorescence on current multi-band $X_{\mathrm{CO}_{2}}$ retrievals employing the $\mathrm{O}_{2}$ Aband. Neglect of fluorescence leads to biases in retrieved aerosol height and/or surface pressure, which propagate into $X_{\mathrm{CO}_{2}}$. Typical errors of a variety of retrieval setups range from a positive $0.5-1 \mathrm{ppm}$ bias if fluorescence constitutes $1 \%$ of the continuum level radiance. Even though this bias is well below $1 \%$, it will be spatially correlated with gross primary production and thus must not be neglected. We show that the bias can be eliminated if fluorescence is implemented 
as a state vector element in the full-physics retrieval algorithm. However, interference of fluorescence with scattering state vector elements leads to a sub-optimal fit of the fluorescence signal itself, though this may be due to deficiencies in our chosen implementation. We show that a proposed NIR fluorescence fit using Fraunhofer lines only (Frankenberg et al., 2011a) results in a much more stable and accurate fit of the NIR chlorophyll fluorescence signal. It is further shown that chlorophyll fluorescence retrieved in this way is only moderately susceptible to the impact of atmospheric scattering, with most of the signal retained even in the presence of moderate clouds (optical depths $<5$ ). It can be concluded that chlorophyll fluorescence not only offers the most direct proxy for gross primary production (as shown in Frankenberg et al., 2011b), but that its retrieval is, unlike traditional optical parameters, much more robust and less affected by fractional cloud-cover and seasonal variations in aerosol optical depth. The only drawback of current satellites such as GOSAT or in the future OCO-2 is the high single measurement noise. However, we show that simple modifications to the instrument design, in particular the extension of the spectral range to shorter wavelengths, can largely reduce measurement noise, paving the way towards future, more dedicated fluorescence missions.

Acknowledgements. The research described in this paper was carried out by the Jet Propulsion Laboratory, California Institute of Technology, under a contract with the National Aeronautics and Space Administration. Government Sponsorship acknowledged. We appreciate the intense discussions at AMTD, which helped improve our manuscript.

Edited by: M. Weber

\section{References}

Baker, N.: Chlorophyll fluorescence: a probe of photosynthesis in vivo, Plant Biol., 59, 89, available at: http://www.genomics.wsu.edu/pages/teaching/Hort416516/ PDFs/Baker2008ChlFluorescence.pdf, 2008.

Beer, C., Reichstein, M., Tomelleri, E., Ciais, P., Jung, M., Carvalhais, N., Rodenbeck, C., Arain, M., Baldocchi, D., and Bonan, G.: Terrestrial gross carbon dioxide uptake: global distribution and covariation with climate, Science, 329, 834-838, doi:10.1126/science.1184984, 2010.

Bösch, H., Toon, G., Sen, B., Washenfelder, R., Wennberg, P., Buchwitz, M., de Beek, R., Burrows, J., Crisp, D., and Christi, M.: Space-based near-infrared $\mathrm{CO}_{2}$ measurements: testing the orbiting carbon observatory retrieval algorithm and validation concept using SCIAMACHY observations over Park Falls, Wisconsin, J. Geophys. Res., 111, 0148-0227, 2006.

Butz, A., Hasekamp, O. P., Frankenberg, C., and Aben, I.: Retrievals of atmospheric $\mathrm{CO}_{2}$ from simulated space-borne measurements of backscattered near-infrared sunlight: accounting for aerosol effects, Appl. Opt., 48, 3322-3336, 2009.
Butz, A., Guerlet, S., Hasekamp, O., Schepers, D., Galli, A., Aben, I., Frankenberg, C., Hartmann, J. M., Tran, H., Kuze, A., Keppel-Aleks, G., Toon, G., Wunch, D., Wennberg, P., Deutscher, N., Griffith, D., Macatangay, R., Messerschmidt, J., Notholt, J., and Warneke, T.: Toward accurate $\mathrm{CO}_{2}$ and $\mathrm{CH}_{4}$ observations from GOSAT, Geophys. Res. Lett., 38, L14812, doi:10.1029/2011GL047888, 2011.

Crisp, D., Atlas, R. M., Breon, F.-M., Brown, L. R., Burrows, J. P., Ciais, P., Connor, B. J., Doney, S. C., Fung, I. Y., Jacob, D. J., Miller, C. E., O'Brien, D., Pawson, S., Randerson, J. T., Rayner, P., Salawitch, R. J., Sander, S. P., Sen, B., Stephens, G. L., Tans, P. P., Toon, G. C., Wennberg, P. O., Wofsy, S. C., Yung, Y. L., Kuang, Z., Chudasama, B., Sprague, G., Weiss, B., Pollock, R., Kenyon, D., and Schroll, S.: The orbiting carbon observatory (OCO) mission, Adv. Space Res., 34, 700-709, 2004.

Crisp, D., Fisher, B. M., O’Dell, C., Frankenberg, C., Basilio, R., Bösch, H., Brown, L. R., Castano, R., Connor, B., Deutscher, N. M., Eldering, A., Griffith, D., Gunson, M., Kuze, A., Mandrake, L., McDuffie, J., Messerschmidt, J., Miller, C. E., Morino, I., Natraj, V., Notholt, J., O’Brien, D., Oyafuso, F., Polonsky, I., Robinson, J., Salawitch, R., Sherlock, V., Smyth, M., Suto, H., Taylor, T., Thompson, D. R., Wennberg, P. O., Wunch, D., and Yung, Y. L.: The ACOS $X_{\mathrm{CO}_{2}}$ retrieval algorithm, Part 2: Global $X_{\mathrm{CO}_{2}}$ data characterization, Atmos. Meas. Tech. Discuss., 5, 1-60, doi:10.5194/amtd-5-12012, 2012.

Damm, A., Elbers, J., Erler, A., Gioli, B., Hamdi, K., Hutjes, R., Kosvancova, M., Meroni, M., Miglietta, F., Moersch, A., Moreno, J., Schickling, A., Sonnenschein, R., Udelhoven, T., Linden, S. V. D., Hostert, P., and Rascher, U.: Remote sensing of sun-induced fluorescence to improve modeling of diurnal courses of gross primary production (GPP), Global Change Biol., 16, 171-186, doi:10.1111/j.1365-2486.2009.01908.x, 2010.

Daumard, F., Champagne, S., Fournier, A., Goulas, Y., Ounis, A., Hanocq, J.-F., and Moya, I.: A field platform for continuous measurement of canopy fluorescence, IEEE T. Geosci. Remote, 48, 3358-3368, doi:10.1109/TGRS.2010.2046420, available online: http://ieeexplore.ieee.org/xpls/abs_all.jsp?arnumber= $5477165 \mathrm{tag}=1,2010$.

Entcheva Campbell, P.-K., Middleton, E.-M., Corp, L.-A., and Kim, M.-S.: Contribution of chlorophyll fluorescence to the apparent vegetation reflectance, Sci. Total Environ., 404, 433-439, 2008.

Flexas, J., Escalona, J., Evain, S., Gulías, J., Moya, I., Osmond, C., and Medrano, H.: Steady-state chlorophyll fluorescence (Fs) measurements as a tool to follow variations of net $\mathrm{CO}_{2}$ assimilation and stomatal conductance during water-stress in $\mathrm{C}_{3}$ plants, Physiol. Plant., 114, 231-240, 2002.

Frankenberg, C., Butz, A., and Toon, G. C.: Disentangling chlorophyll fluorescence from atmospheric scattering effects in $\mathrm{O}_{2}$ A-band spectra of reflected sun-light, Geophys. Res. Lett., 38, L03801, doi:10.1029/2010GL045896, 2011a.

Frankenberg, C., Fisher, J., Worden, J., Badgley, G., Saatchi, S., Lee, J.-E., Toon, G., Butz, A., Jung, M., Kuze, A., and Yokota, T.: New global observations of the terrestrial carbon cycle from GOSAT: patterns of plant fluorescence with gross primary productivity, Geophys. Res. Lett., 38, L17706, doi:10.1029/2011GL048738, 2011b. 
Guanter, L., Alonso, L., Gómez-Chova, L., Meroni, M., Preusker, R., Fischer, J., and Moreno, J.: Developments for vegetation fluorescence retrieval from spaceborne high-resolution spectrometry in the $\mathrm{O}_{2}-\mathrm{A}$ and $\mathrm{O}_{2}$-B absorption bands, J. Geophys. Res., 115, D19303, doi:10.1029/2009JD013716, 2010.

Guanter, L., Frankenberg, C., Dudhia, A., Lewis, P. E., GómezDans, J., Kuze, A., Suto, H., and Grainger, R. G.: Retrieval and global assessment of terrestrial chlorophyll fluorescence from GOSAT space measurements, Remote Sens. Environ., 121, 236$251,2012$.

Hamazaki, T., Kaneko, Y., Kuze, A., and Kondo, K.: Fourier transform spectrometer for Greenhouse Gases Observing Satellite (GOSAT), Proc. SPIE, 73, 5659, doi:10.1117/12.581198, 2005.

Holben, B. N., Eck, T. F., Slutsker, I., Tanre, D., Buis, J. P., Setzer, A., Vermote, E., Reagan, J. A., Kaufman, Y., Nakajima, T., Lavenu, F., Jankowiak, I., and Smirnov, A.: AERONET - a federated instrument network and data archive for aerosol characterization, Remote Sens. Environ., 66, 1-16, 1998.

Joiner, J., Yoshida, Y., Vasilkov, A. P., Yoshida, Y., Corp, L. A., and Middleton, E. M.: First observations of global and seasonal terrestrial chlorophyll fluorescence from space, Biogeosciences, 8, 637-651, doi:10.5194/bg-8-637-2011, 2011.

Joiner, J., Yoshida, Y., Vasilkov, A. P., Middleton, E. M., Campbell, P. K. E., Yoshida, Y., Kuze, A., and Corp, L. A.: Filling-in of near-infrared solar lines by terrestrial fluorescence and other geophysical effects: simulations and space-based observations from SCIAMACHY and GOSAT, Atmos. Meas. Tech., 5, 809-829, doi:10.5194/amt-5-809-2012, 2012.

Krause, G. and Weis, E.: Chlorophyll fluorescence as a tool in plant physiology, Photosynth. Res., 5, 139-157, 1984.

Krause, G. and Weis, E.: Chlorophyll fluorescence and photosynthesis - the basics, Annu. Rev. Plant. Phys., 42, 313-349, 1991.

Kuze, A., Suto, H., Nakajima, M. and Hamazaki, T.: Thermal and near infrared sensor for carbon observation Fourier-transform spectrometer on the Greenhouse Gases Observing Satellite for greenhouse gases monitoring, Appl. Opt., 48, 6716-6733, 2009.

Liou, K. N.: An Introduction to Atmospheric Radiation, Academic Press, San Diego, 2002.

Meroni, M., Rossini, M., Guanter, L., Alonso, L., Rascher, U., Colombo, R., and Moreno, J.: Remote sensing of solar-induced chlorophyll fluorescence: review of methods and applications, Remote Sens. Environ., 113, 2037-2051, doi:10.1016/j.rse.2009.05.003, 2009.

Moya, I., Camenen, L., Evain, S., Goulas, Y., Cerovic, Z., Latouche, G., Flexas, J., and Ounis, A.: A new instrument for passive remote sensing 1. Measurements of sunlight-induced chlorophyll fluorescence, Remote Sens. Environ., 91, 186-197, doi:10.1016/j.rse.2004.02.012, 2004.

O’Brien, D. M., Polonsky, I., O'Dell, C., and Carheden, A.: Orbiting Carbon Observatory (OCO), algorithm theoretical basis document: the OCO simulator, Technical report ISSN 0737-535285, Cooperative Institute for Research in the Atmosphere, Colorado State University, 2009.

O'Dell, C.: Acceleration of multiple-scattering, hyperspectral radiative transfer calculations via low-streams interpolation, J. Geophys. Res., 115, D10206, doi:10.1029/2009JD012803, 2010.
O’Dell, C. W., Connor, B., Bösch, H., O’Brien, D., Frankenberg, C., Castano, R., Christi, M., Eldering, D., Fisher, B., Gunson, M., McDuffie, J., Miller, C. E., Natraj, V., Oyafuso, F., Polonsky, I., Smyth, M., Taylor, T., Toon, G. C., Wennberg, P. O., and Wunch, D.: The ACOS $\mathrm{CO}_{2}$ retrieval algorithm - Part 1: Description and validation against synthetic observations, Atmos. Meas. Tech., 5, 99-121, doi:10.5194/amt-5-99-2012, 2012.

Parker, R., Boesch, H., Cogan, A., Fraser, A., Feng, L., Palmer, P. I., Messerschmidt, J., Deutscher, N., Griffith, D. W. T., Notholt, J., Wennberg, P. O., and Wunch, D.: Methane observations from the greenhouse gases observing satellite: comparison to groundbased TCCON data and model calculations, Geophys. Res. Lett., 38, L15807, doi:10.1029/2011GL047871, 2011.

Plascyk, J. and Gabriel, F.: The Fraunhofer line discriminator MKII - an airborne instrument for precise and standardized ecological luminescence measurement, IEEE T. Instrum. Meas., 24, 306313, 1975.

Pfuendel, E..: Estimating the contribution of Photosystem I to total leaf chlorophyll fluorescence, Photosynthesis Research, 56, 185195, doi:10.1023/A:1006032804606, 1998.

Rascher, U., Agati, G., Alonso, L., Cecchi, G., Champagne, S., Colombo, R., Damm, A., Daumard, F., de Miguel, E., Fernandez, G., Franch, B., Franke, J., Gerbig, C., Gioli, B., Gómez, J. A., Goulas, Y., Guanter, L., Gutiérrez-de-laCámara, Ó., Hamdi, K., Hostert, P., Jiménez, M., Kosvancova, M., Lognoli, D., Meroni, M., Miglietta, F., Moersch, A., Moreno, J., Moya, I., Neininger, B., Okujeni, A., Ounis, A., Palombi, L., Raimondi, V., Schickling, A., Sobrino, J. A., Stellmes, M., Toci, G., Toscano, P., Udelhoven, T., van der Linden, S., and Zaldei, A.: CEFLES2: the remote sensing component to quantify photosynthetic efficiency from the leaf to the region by measuring sun-induced fluorescence in the oxygen absorption bands, Biogeosciences, 6, 1181-1198, doi:10.5194/bg6-1181-2009, 2009.

Rodgers, C. D.: Inverse Methods for Atmospheric Sounding: Theory and Practice, World Scientific, Singapore, 2000.

Salstein, D. A., Ponte, R. M., and Cady-Pereira, K.: Uncertainties in atmospheric surface pressure fields from global analyses, J. Geophys. Res., 113, D14107, doi:10.1029/2007JD009531, 2008.

Sanghavi, S., Martonchik, J. V., Landgraf, J., and Platt, U.: Retrieval of the optical depth and vertical distribution of particulate scatterers in the atmosphere using $\mathrm{O}_{2} \mathrm{~A}$ - and B-band SCIAMACHY observations over Kanpur: a case study, Atmos. Meas. Tech., 5, 1099-1119, doi:10.5194/amt-5-1099-2012, 2012.

Schneising, O., Buchwitz, M., Burrows, J. P., Bovensmann, H., Reuter, M., Notholt, J., Macatangay, R., and Warneke, T.: Three years of greenhouse gas column-averaged dry air mole fractions retrieved from satellite - Part 1: Carbon dioxide, Atmos. Chem. Phys., 8, 3827-3853, doi:10.5194/acp-8-3827-2008, 2008.

Van der Tol, C., Verhoef, W., and Rosema, A.: A model for chlorophyll fluorescence and photosynthesis at leaf scale, Agr. Forest Meteorol., 149(1), 96-105, 2009.

Yoshida, Y., Ota, Y., Eguchi, N., Kikuchi, N., Nobuta, K., Tran, H., Morino, I., and Yokota, T.: Retrieval algorithm for $\mathrm{CO}_{2}$ and $\mathrm{CH}_{4}$ column abundances from short-wavelength infrared spectral observations by the Greenhouse gases observing satellite, Atmos. Meas. Tech., 4, 717-734, doi:10.5194/amt-4-717-2011, 2011. 